\title{
Autoresuscitation (Lazarus phenomenon) after termination of cardiopulmonary resuscitation - a scoping review
}

\author{
Les Gordon ${ }^{1,2}$, Mathieu Pasquier ${ }^{2,3}$, Hermann Brugger ${ }^{2,4}$ and Peter Paal ${ }^{2,5^{*}}$ (D)
}

\begin{abstract}
Background: Autoresuscitation describes the return of spontaneous circulation after termination of resuscitation (TOR) following cardiac arrest (CA). We aimed to identify phenomena that may lead to autoresuscitation and to provide guidance to reduce the likelihood of it occurring.

Materials and methods: We conducted a literature search (Google Scholar, MEDLINE, PubMed) and a scoping review according to PRISMA-SCR guidelines of autoresuscitation cases where patients undergoing CPR recovered circulation spontaneously after TOR with the following criteria: 1) CA from any cause; 2) CPR for any length of time; 3) A point was reached when it was felt that the patient had died; 4) Staff declared the patient dead and stood back. No further interventions took place; 5) Later, vital signs were observed. 6) Vital signs were sustained for more than a few seconds, such that staff had to resume active care.

Results: Sixty-five patients with ROSC after TOR were identified in 53 articles (1982-2018), 18 (28\%) made a full recovery. Conclusions: Almost a third made a full recovery after autoresuscitation. The following reasons for and recommendations to avoid autoresuscitation can be proposed: 1) In asystole with no reversible causes, resuscitation efforts should be continued for at least $20 \mathrm{~min}$; 2) CPR should not be abandoned immediately after unsuccessful defibrillation, as transient asystole can occur after defibrillation; 3) Excessive ventilation during CPR may cause hyperinflation and should be avoided; 4) In refractory CA, resuscitation should not be terminated in the presence of any potentially-treatable cardiac rhythm; 5) After TOR, the casualty should be observed continuously and ECG monitored for at least 10 min.
\end{abstract}

Keywords: Autoresuscitation, Cardiopulmonary resuscitation, Emergency medicine, Hyperventilation, Lazarus phenomenon, Resuscitation, Resuscitation orders

\section{Introduction}

Autoresuscitation describes the return of spontaneous circulation (ROSC) after termination of resuscitation (TOR) following cardiac arrest (CA), when resuscitation has been attempted but has been deemed unsuccessful and abandoned [1]. It was first described in 1982 [2] and has been seen in out-of-hospital and in-hospital situations. It is sometimes called the "Lazarus Phenomenon" or "Lazarus Syndrome" after Lazarus, who was raised from the dead after 4 days by Jesus. The actual incidence

\footnotetext{
*Correspondence: peter.paal@icloud.com

${ }^{2}$ International Commission for Mountain Emergency Medicine (ICAR MEDCOM), Zermatt, Switzerland

${ }^{5}$ Department of Anaesthesiology and Intensive Care, Hospitallers Brothers Hospital, Paracelsus Medical University, Salzburg, Austria

Full list of author information is available at the end of the article
}

of autoresuscitation is unknown but it is not rare, as surveys have shown that $37-50 \%$ of intensive care or prehospital emergency physicians have encountered it in clinical practice [3-6]. This means that there may be many unreported cases, since there are $\approx 1900$ Intensive Care consultants in the UK alone. It is believed that the condition is grossly under-reported, partly because of fear of legal repercussions [7-9]. The implications of even a few reports of autoresuscitation are significant, not only because it can cause dismay and distress to healthcare professionals, bystanders and family, but also because delayed ROSC could lead to questions being asked about whether resuscitation had been conducted properly and whether it was stopped prematurely [1013]. Personnel delivering resuscitation should know

(c) The Author(s). 2020 Open Access This article is distributed under the terms of the Creative Commons Attribution 4.0 International License (http://creativecommons.org/licenses/by/4.0/), which permits unrestricted use, distribution, and 
about the existence of autoresuscitation before being confronted with it $[4,14]$. It was therefore decided to review the reported cases of autoresuscitation in patients undergoing $\mathrm{CPR}$, to identify any factors that may contribute to it, and highlight changes in practice that could potentially reduce the likelihood of it occurring. This article maps the evidence about autoresuscitation, identifies the main theories and knowledge gaps, and proposes guidance on issues during resuscitation, and when confirming death, that could have a bearing on whether autoresuscitation will occur.

\section{Methods}

Cases of autoresuscitation were identified and selected through a scoping literature review. This method was chosen as it was felt to be most appropriate for identifying and mapping the available evidence on a very specific topic with a low-evidence base, when it is still unclear what other, more specific questions regarding its aetiology should be posed, and where evidence is still emerging [15]. We complied as much as possible with the Prisma-ScR scoping review checklist and guidelines [16]. We did not establish nor publish a priori a protocol for this study, and to our knowledge, there is not one currently in existence. For the purposes of this review, case reports conformed to all of the following criteria: 1) CA occurred from any cause; 2 ) Resuscitation attempts were performed (Basic Life Support or Advanced Life Support) for any length of time; 3) A point was reached when it was felt that either the patient had actually died (typically, persistent asystole) or a refractory arrhythmia occurred e.g. PEA, VF, that was not felt to be amenable to treatment; 4) Staff then declared the patient to be dead and stood back. No further interventions took place; 5) Later, signs of life were observed e.g. respiratory movements, electrocardiogram (ECG). Importantly, cases with transient ECG resumption compatible with cardiac output but no pulse were excluded. 6) The signs of life were sustained for more than a few seconds, such that staff had to resume active patient care. Patients who were expected to die, and therefore did not receive full Basic or Advanced Life Support, have not been included in this review. In addition, spontaneous reversion of VF to sinus rhythm with brief or no resuscitation attempts has been well documented for $>60$ years [17-20] and is also not included.

We searched the literature up to 20th August 2019 with Google Scholar, MEDLINE and PubMed using the following terms alone and in combination: "Lazarus Phenomenon"; "Lazarus Syndrome"; "Autoresuscitation" or "Auto-resuscitation". The composite search string used was ("lazarus phenomenon" OR "lazarus syndrome" OR "autoresuscitation" OR "auto-resuscitation") for Google Scholar and (("lazarus phenomenon" [All Fields] OR "lazarus syndrome"[All Fields]) OR "autoresuscitation"[All Fields]) OR "auto-resuscitation"[All Fields] for MEDLINE and PubMed. Articles of any type were included in this review, e.g. case reports and series; cohort and prospective studies and other systematic reviews, provided that they had been published in peer-reviewed journals. To expand the number of relevant retrieved articles, we then used two further search procedures. By placing the title of each article retrieved into the search field, we used the options to seek "Related articles" in Google Scholar and "Similar articles" in MEDLINE and PubMed. Articles in English, French, German, Russian, Spanish and Turkish were included. Finally, we searched the bibliography of the retrieved articles for additional articles that had not been picked up by the original searches.

The following data were collected for every case: age, sex, duration of resuscitation, rhythm when resuscitation was abandoned (e.g. asystole, pulseless electric activity (PEA), ventricular fibrillation (VF)), and the time when ROSC was first noticed. Outcome parameters included the cause of death or survival to hospital discharge (as appropriate) [21] and the neurological outcome (Cerebral Performance Category (CPC)) [22].

One author (LG) performed the literature search and built the database. In cases of doubt regarding the inclusion of a given case, the case was independently assessed for eligibility by the co-authors. All reports that clearly described a case of autoresuscitation were included, no matter how much detail was included. Descriptive statistics included frequencies, means and standard deviations, or median and interquartile range (IQR) to help better understand the scope of the problem. Groups were compared using Pearson's Chi-square or Fischer's exact tests, Student's t-test, or the Wilcoxon rank-sum test as appropriate. The data retrieved from the database were exported to Stata version 14 (Stata Corporation, College Station, TX). A bilateral $p$-value $<0.05$ was considered to indicate a significant difference.

\section{Results}

The literature search generated 1372 publications, 53 references with 63 patients for which outcome was available were included (Fig. 1). All the references were retrospective case reports of which five [2, 13, 23-25] described two patients, and one [26] described a series of five patients (Additional file 1: Table S1). Brief clinical details of the cases included in this review are reported in Additional file 2. We also included three published reviews and a prospective study (Additional file 3 ) in the qualitative synthesis.

We included 34 out-of-hospital and 29 in-hospital CAs. The mean age of the patients was of $61 \pm 24$ (range 9 months - 97 years), the majority (68\%) occurred in patients $>60$ years old. The rhythm when CPR was first abandoned was asystole in $38(70 \%)$ of the 54 patients for which this information was available (12 survivors; 26 non-survivors), PEA 
Records identified through database searching $(n=2982)$

- $\quad$ PubMed $(n=186)$, Medline $(n=186)$, Google Scholar $(n=2610)$ using combinations of the following keywords: ("Lazarus Phenomenon"; "Lazarus syndrome”; Autoresuscitation and Auto-resuscitation) up to 20.8 .2019

Additional references included from
other sources (references from case reports $(n=10)$

2 publications ( 2 patients) excluded as no outcome data

2 publications ( 2 patients) excluded because CPR not attempted

- 1 publication (3 patients) excluded (PEA due to excessive ventilation. ROSC occurred when ventilation ceased)

- 2 publications ( 7 patients)excluded as brief autoresuscitation after Withdrawal of Life Sustaining Therapy and no CPR

- 2 publications (13 patients) excluded as no clinical details provided

1 publication ( 3 patients) excluded as ROSC occurred after mechanical CPR instituted for organ preservation

Publications included $(n=53)$

Patients included in the database $(n=63)$

Fig. 1 Flowchart of patient selection

in 12/54 (22\%) (3 survivors; 9 non-survivors), and VF in 4/54 (7\%) (survivors only). Median duration of resuscitation was 30 min (IQR 18-40; range 0-90 min). Resuscitation attempts were performed for $<20 \mathrm{~min}$ (the time often recommended before abandoning resuscitation) [27-32] in 14 of 63 cases (22\%). Signs of life were first noticed within $5 \mathrm{~min}$ in $30 / 63$ cases $(47 \%)$ cases and at $6-10 \mathrm{~min}$ in $14 / 63$ cases $(22 \%)$ (median of $5 \mathrm{~min}$ (IQR 3-10; range 0-220 $\mathrm{min}$ )) after resuscitation had been stopped. In the remaining cases, signs of life were not noticed until later or not recorded. In some cases, signs of life were only observed several hours after "death" was supposed to have occurred. Out of the 63 patients, 22
(35\%) survived to hospital discharge, most (18; 82\%) with good neurological outcome (Table 1). Forty-one patients died, the majority whilst still in hospital (Table 2) due to severe hypoxic brain damage or cardiac problems in most cases $(28 / 41 ; 68 \%)$, while $4 / 41(10 \%)$ initially fully recovered from arrest (CPC 1 or 2) but died due to other causes. Data on outcome was missing for two additional patients (Table 3). There was no difference between survivors and nonsurvivors regarding age $(p=0.18)$, duration of resuscitation $(p=0.47)$, and signs of life first noticed $(p=0.80)$. The rhythm when resuscitation was abandoned was associated with survival, as all four patients with VF survived, compared 


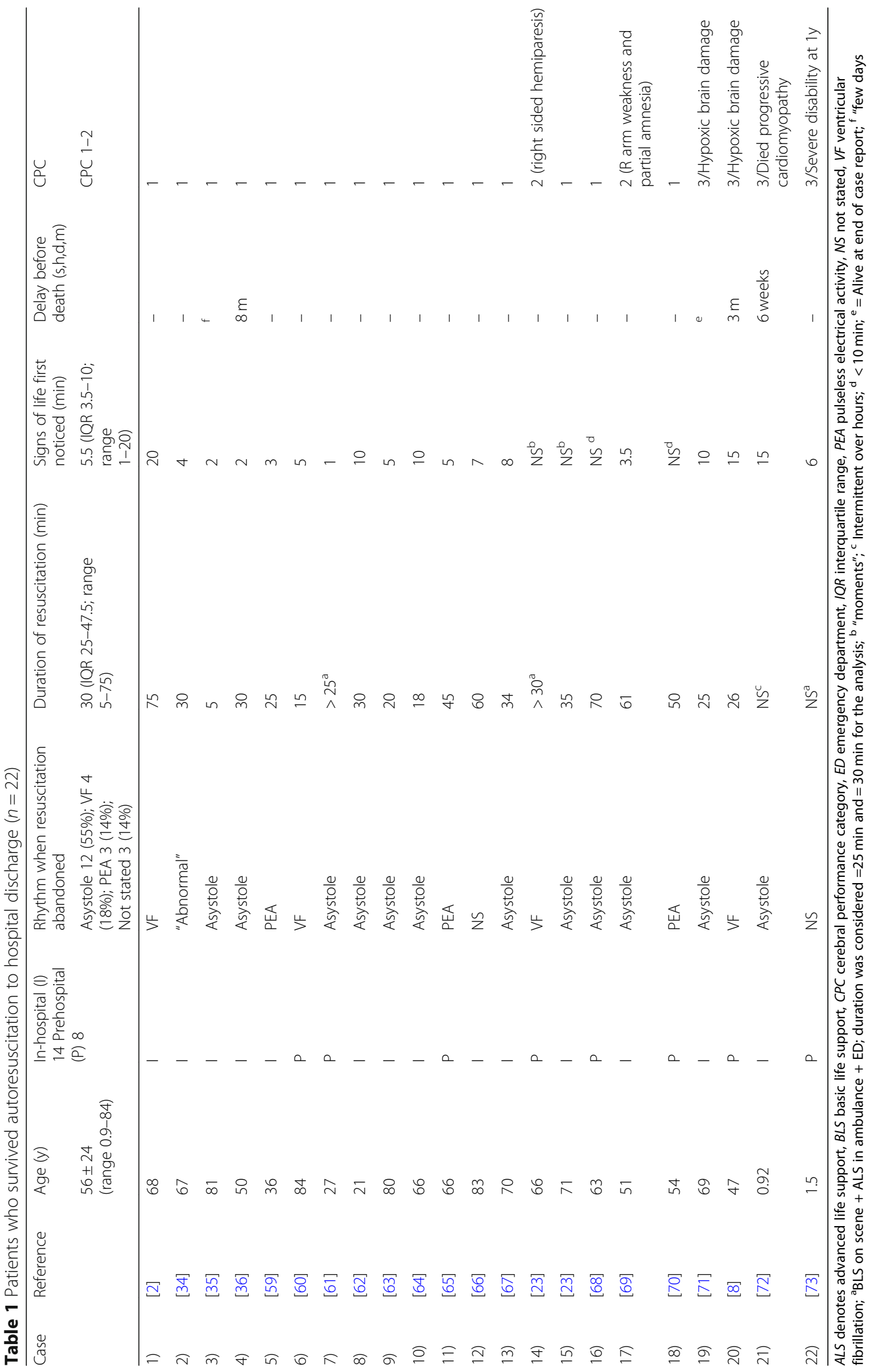




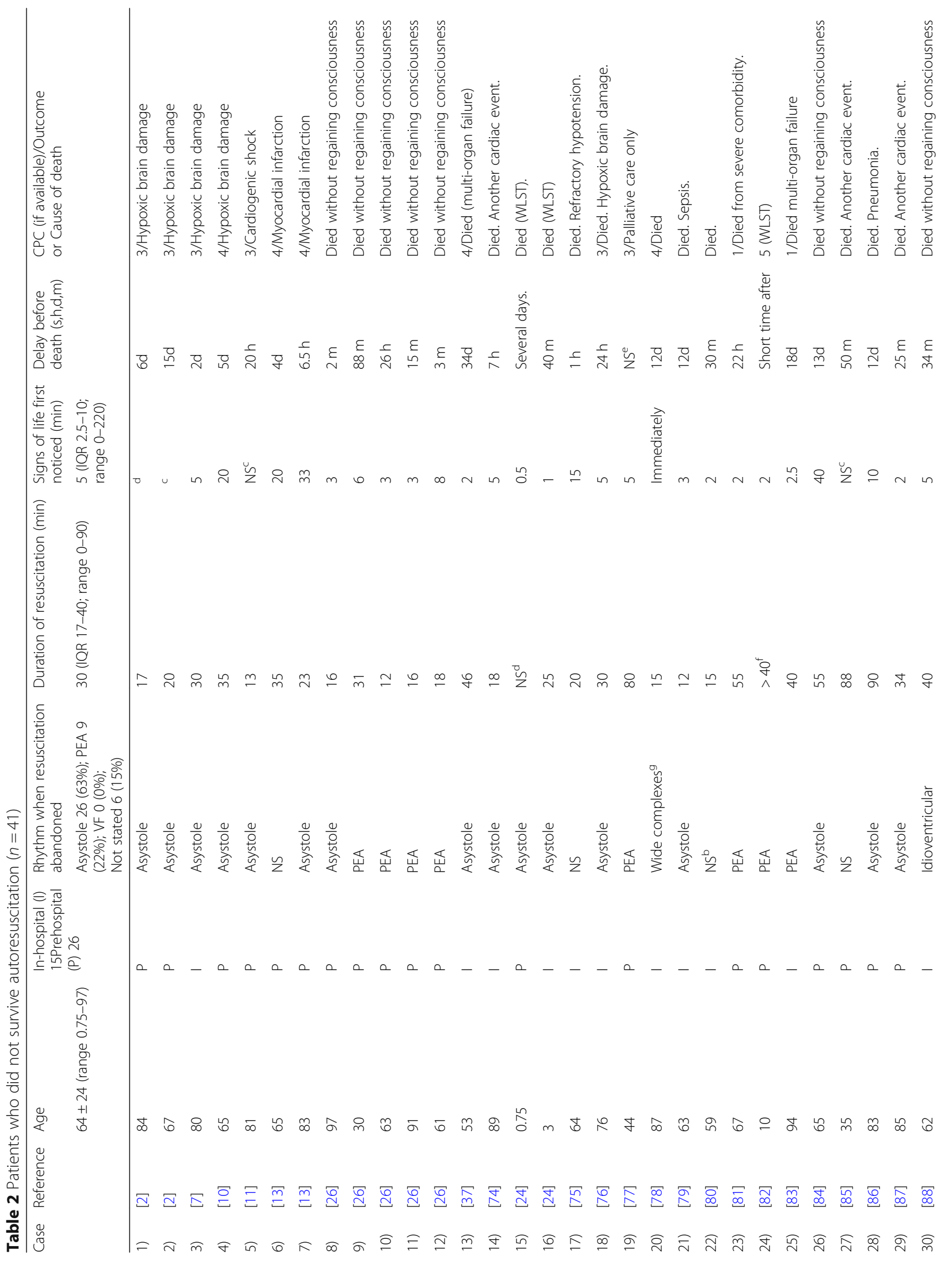




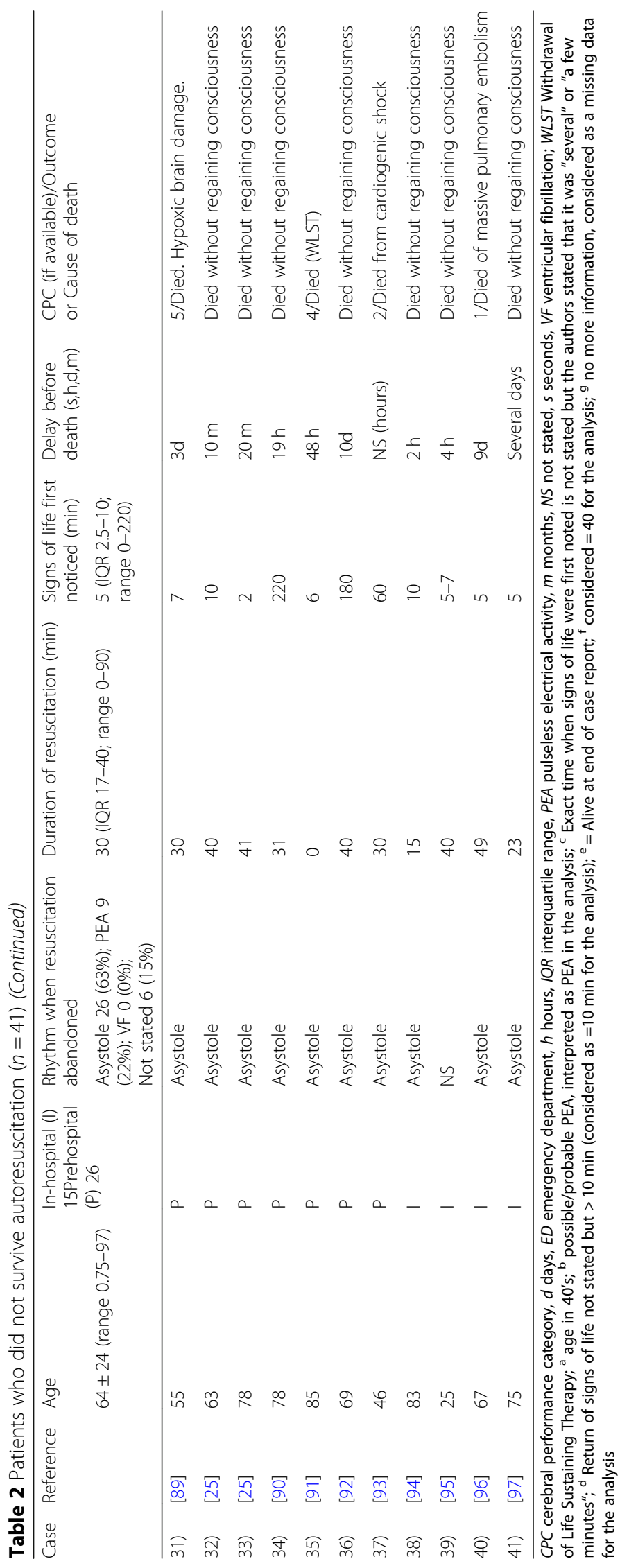


Table 3 Unknown final outcome of autoresuscitation $(n=2)$

\begin{tabular}{llllllll}
\hline Case & Ref & Age & $\begin{array}{l}\text { Rhythm when resuscitation } \\
\text { abandoned }\end{array}$ & $\begin{array}{l}\text { Duration of } r \\
\text { esuscitation }(\mathrm{min})\end{array}$ & $\begin{array}{l}\text { Signs of life first } \\
\text { noticed (min) }\end{array}$ & $\begin{array}{l}\text { Delay before death } \\
\text { CPC (if available)/Outcome or } \\
\text { cause of death }\end{array}$ \\
\hline 1) & {$[98]$} & 93 & NS & 6 & 5 & NS & Outcome not stated \\
2) & {$[99]$} & 40 & Asystole & 45 & 30 & NS & Outcome not stated \\
\hline
\end{tabular}

CPC denotes cerebral performance category, NS not stated

with $12 / 38(32 \%)$ and $3 / 12(35 \%)$ of those with asystole and PEA, respectively $(p=0.017)$.

The definitions of autoresuscitation in published case reports vary but all contain the same two elements: 1 ) attempted and abandoned resuscitation attempts following CA, 2) subsequent ROSC without medical intervention (Additional file 4).

\section{Discussion}

The most important finding is that about 30\% of patients made a good recovery after death had been diagnosed, so autoresuscitation is of major significance and puts a focus on resuscitation practice, the decision to terminate resuscitation and diagnosis of death. Although the biblical Lazarus rose from the dead without resuscitation attempts, there are no case reports of it occurring in someone who has died without CPR performed beforehand [9, 33]. Almost all cases of autoresuscitation occurred after CPR following non-traumatic $\mathrm{CA}$; there is only one report following traumatic CA [34] and four others associated with major haemorrhage [26, 35-37]. Therefore, it has been suggested that autoresuscitation is due to the medical interventions that were performed during resuscitation, but their effectiveness was delayed for some reason [38]. Cases occurring in patients who have undergone withdrawal of life-sustaining treatment were short-lived [39], apart from the subgroup of intended organ donors in which death was thought to have occurred and the circulation was subsequently maintained by artificial means [40, 41]. It is essential to consider possible mechanisms of autoresuscitation because this has potential implications for the way resuscitation is performed. A clear mechanism for autoresuscitation has been identified in only a few cases. The pathophysiologic factors (possibly in combination) that are thought to contribute to autoresuscitation are listed in Table 4 and derived from the conclusions of the authors of the published case reports and studies. Autoresuscitation has been reported more frequently in adults than children $[3,33]$.

Death may be defined as the irreversible cessation of vital functions, including absence of circulation, spontaneous breathing, and whole-brain death when no confounding factors are present [27, 42, 43]. Doctors therefore diagnose death based on the absence of functions that are fundamental for life. The Academy of UK Medical Royal Colleges guidelines specify that there should be an absence of heart sounds, a central pulse on palpation, pupillary responses to light, corneal reflexes, and any motor response to supra-orbital pressure before confirming death [42]. In an advanced care setting, these findings can be supplemented with: asystole on a continuous ECG, absence of pulsatile flow with intra-arterial monitoring or the absence of contractile activity using echocardiography [42]. Although patients exhibiting the above clinical findings are assumed to have passed the "point of no return" and become unsalvageable, in fact death is not an instantaneous event but takes place over time. Sporadic ECG activity in the absence of a circulation can occur for many minutes after death is diagnosed [1, 33, 39, 44 ], and this can confound the Academy's use of asystole as an indicator of death. Thus, an essential requirement when defining autoresuscitation is the presence of a circulation, because death determination depends on the cessation of circulation, not just of cardiac electrical activity [45]. In addition, a recent animal study indicated that sporadic cortical neuronal activity may be present for 2 hours following cardiac arrest [46]. If ECG activity resumes, it is important to establish if it is in isolation or whether ROSC has occurred [45]. Importantly, arterial pulselessness and asystole for a short period, e.g. immediately after defibrillation [23, 47], cannot reliably establish that irreversible cessation of cardiac and neurological function has occurred [48]. Finally, several autoresuscitation case-reports have occurred in the presence of a discernible cardiac rhythm (refractory VF or PEA, wide QRS complexes, extreme bradycardia) i.e. not asystole. Therefore, caution is advised before abandoning resuscitation in the presence of an ECG that is potentially treatable or compatible with life [26].

The Academy also advises that the person responsible for confirming death should observe the patient for "a minimum of five minutes to establish that irreversible cardiorespiratory arrest has occurred" [42]. The observation period after TOR is crucial and could leave carers open to the criticism that resuscitation was terminated prematurely [10] if an adequate period of observation after TOR is not employed. Importantly, the $5 \mathrm{~min}$ observation period [42] will potentially miss almost half of the autoresuscitation cases identified in this review. Although a care provider will potentially 


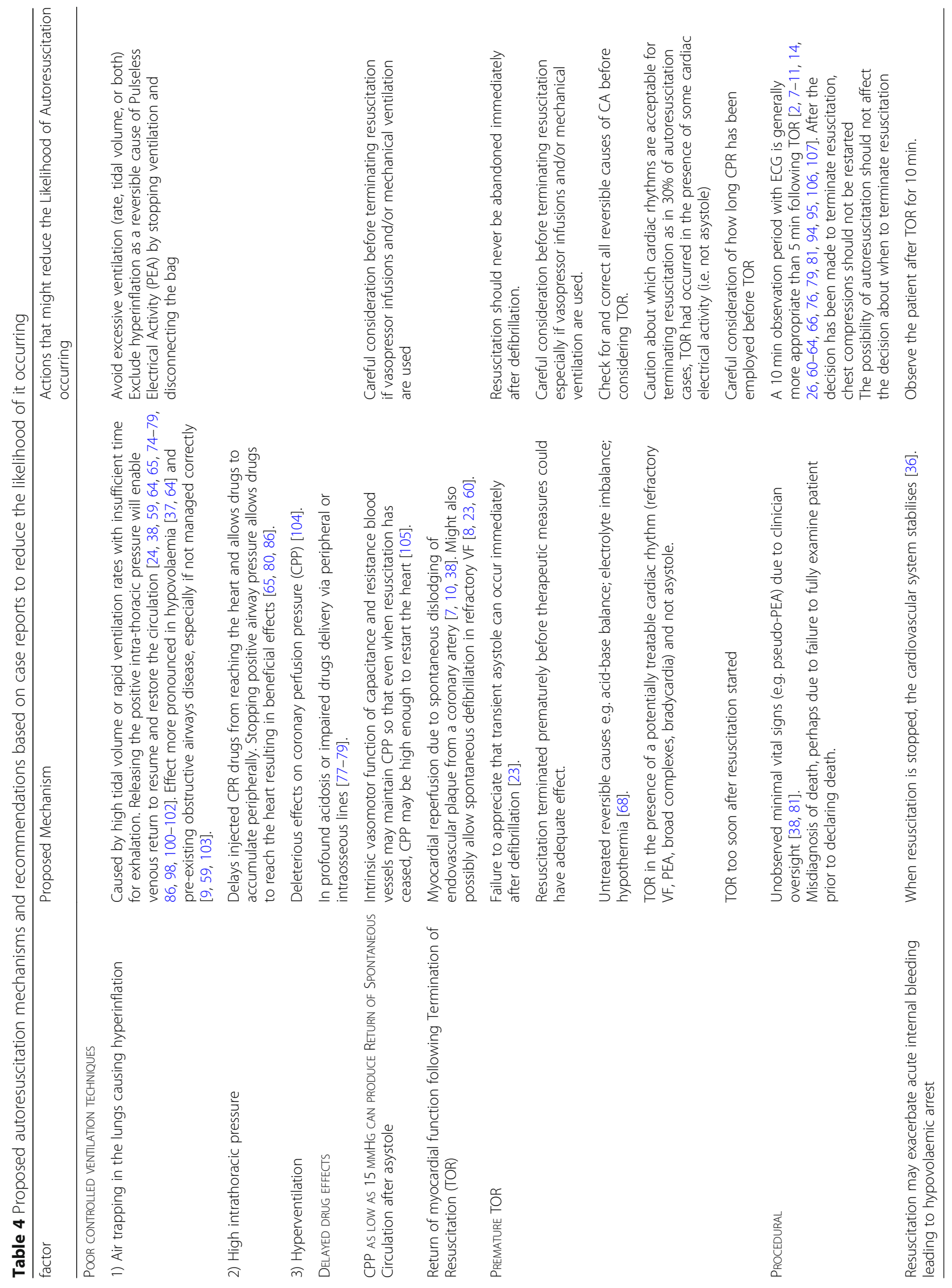


always be open to the charge that the resuscitation efforts were ended prematurely, regardless of the period of observation following termination of efforts, it is unreasonable to recommend that a patient is observed for a prolonged period of time after TOR solely in case autoresuscitation occurs. There has to be a balance between stopping the observation period prematurely at one extreme and waiting for a protracted period of time at the other. Our analysis of the case reports suggests that increasing from 5 to $10 \mathrm{~min}$ will increase the number of cases of autoresuscitation that will be picked up from $47 \%$ in $\leq 5 \mathrm{~min}$ to $69 \%$ within $10 \mathrm{~min}$, and this increase is advocated by many of the authors of the case reports.

\section{Recommendations}

It has been calculated that a study with $95 \%$ confidence interval and $80 \%$ statistical power would need to document zero cases of autoresuscitation among 10,516 patients just to "rule out" even a rather high autoresuscitation rate of one in 1000 deaths [49]. Therefore, it is unlikely that a formal study that includes sufficient numbers of patients will ever be conducted. Consequently, it is necessary to review the factors that have been identified in actual cases and propose measures that can be taken to reduce the likelihood of autoresuscitation occurring. A summary of these, the rationale underpinning them and the relevant references are detailed in Table 4 . These have been derived from the conclusions of the authors of each individual case report. There are five principal points to consider:

1. Resuscitation attempts should be continued for at least $20 \mathrm{~min}$. Although this is now standard practice, in $22 \%$ of autoresuscitation cases, resuscitation was performed for less than this.

2. Attempt to avoid high intrathoracic pressure and hyperinflation during ventilation, as these are believed to be the underlying mechanism in many of the autoresuscitation case reports. In practice, this means gentle manual ventilation at no more than 12 breaths/minute. In patients with a history of chronic lung disease, it may be helpful to periodically disconnect the breathing circuit to ensure that the lungs are fully deflated before recommencing ventilation to avoid hyperinflation of the chest and thus diminished venous return to the heart.

3. As transient asystole can occur after defibrillation, careful consideration should be given before abandoning resuscitation immediately after an unsuccessful defibrillation attempt.

4. In refractory cardiac arrest, it might be unwise to terminate resuscitation in the presence of any potentially treatable cardiac rhythm, as this can become a perfusing rhythm. If an ECG monitor is not available and the cardiac rhythm is unknown (e.g. as in some Search and Rescue teams staffed by lay people), attempts should be made to get healthcare professional advice before terminating resuscitation.

5. After termination of resuscitation, consider extending the patient observation period from five to 10 min with ECG monitoring. No rules are going to exclude all cases of autoresuscitation but extending the observation period from five to 10 min will increase the safety margin from 47 to $69 \%$. It is important to remember that the quoted times to recognition that the patient was still alive recorded in the case reports are generally not the times that autoresuscitation actually occurred. As explained above, this is because in most cases, patient monitoring was stopped when death was declared, and it was only when something changed e.g. the patient was noticed to be breathing, that it was clear that they were not dead.

\section{Limitations}

This is a scoping review and not a systematic review. More databases could have been accessed. Also, there may be more reports because some older papers published in print are now unavailable. The quality of reporting was generally low (case reports or letters to the editor), and often contained too few data to be included in this review [50]. In most reports, continuous monitoring was switched off once resuscitation had been abandoned, so the time when signs of life were detected is not an accurate guide to when ROSC occurred. This explains at least some of the cases where the time interval from TOR to signs of life detected was prolonged. Given the scarcity of data with autoresuscitation it may be necessary to make recommendations, which are mainly based on case reports and series. Nevertheless, we are not aware of any better method than this scoping review to assess autoresuscitation. Autoresuscitation may be a concern in potential organ donors. This specialist area is covered elsewhere, so it was felt inappropriate to draw it into this discussion $[3,45$, 51-58].

We have attempted to overcome some of the limitations imposed by language restrictions. Another potential limitation is that the search strategy focussed on papers in which the title indicated that the theme of the paper was about autoresuscitation, Lazarus, etc. This was to avoid identifying the many papers in which autoresuscitation is mentioned but only as part of a wider discussion about resuscitation. The recommendations have been based on a small sample size. 


\section{Conclusions}

Almost a third of the patients made a full recovery after autoresuscitation. This emphasises resuscitation should be terminated with caution. The following reasons for and recommendations to avoid autoresuscitation can be given: 1) In asystole with no reversible causes, resuscitation efforts should be continued for at least $20 \mathrm{~min}$; 2) Resuscitation should not be abandoned immediately after unsuccessful defibrillation, as transient asystole can occur after defibrillation; 3) Excessive ventilation during resuscitation may cause hyperinflation and should be avoided; 4) In refractory cardiac arrest, resuscitation should not be terminated in the presence of any potentially-treatable cardiac rhythm; 5) After TOR, the casualty should be observed continuously and ECG monitored for at least $10 \mathrm{~min}$.

\section{Supplementary information}

Supplementary information accompanies this paper at https://doi.org/10. 1186/s13049-019-0685-4.

Additional file 1. Table S1. Year of publication, number of autoresuscitation cases and references reported in this review

Additional file 2. Published autoresuscitation case reports with brief clinical details

Additional file 3. Published reviews and prospective studies

Additional file 4. Published definitions of autoresuscitation

\section{Acknowledgements}

This manuscript has been funded with departmental sources only. The authors thank the Department of Innovation, Research and University of the Autonomous Province of Bozen/Bolzano for covering the Open Access publication costs.

\section{Authors' contributions}

LG provided the idea to this study, performed the literature search and wrote the first draft of the manuscript. LG, MP, HB and PP discussed the findings. MP statistically analyzed the data. MP, HB and PP edited the manuscript. All authors finally agreed on the final version of this manuscript.

\section{Competing interests}

The authors declare that they have no competing interests.

\section{Author details}

${ }^{1}$ Department of Anaesthesia, University Hospitals Morecambe Bay Trust, Royal Lancaster Infirmary, Lancaster, UK. ${ }^{2}$ International Commission for Mountain Emergency Medicine (ICAR MEDCOM), Zermatt, Switzerland. ${ }^{3}$ Emergency Department, Lausanne University Hospital, Lausanne, Switzerland. ${ }^{4}$ Institute of Mountain Emergency Medicine, EURAC research, Bolzano, Italy. ${ }^{5}$ Department of Anaesthesiology and Intensive Care, Hospitallers Brothers Hospital, Paracelsus Medical University, Salzburg, Austria.

\section{Received: 5 September 2019 Accepted: 11 November 2019}

\section{We:}

\section{References}

1. Wijdicks EF, Diringer MN. Electrocardiographic activity after terminal cardiac arrest in neurocatastrophes. Neurology. 2004;62(4):673-4.

2. Linko K, Honkavaara P, Salmenpera M. Recovery after discontinued cardiopulmonary resuscitation. Lancet. 1982:1(8263):106-7.

3. Dhanani S, Ward R, Hornby L, Barrowman NJ, Hornby K, Shemie SD, et al. Survey of determination of death after cardiac arrest by intensive care physicians. Crit Care Med. 2012;40(5):1449-55.
4. Gerard D, Vaux J, Boche T, Chollet-Xemard C, Marty J. Lazarus phenomenon: knowledge, attitude and practice. Resuscitation. 2013;84(12):e153.

5. Wind J, van Mook WN, Dhanani S, van Heurn EW. Determination of death after circulatory arrest by intensive care physicians: A survey of current practice in the Netherlands. J Crit Care. 2016;31(1):2-6.

6. El Dorado County EMS A. Five good reasons for better EMS documentation. Article 2. Proof of Life: Why we must make every possible effort, even when patients 'look' dead [Available from: https://www.edcgov.us/government/ ems/pdf/documents/RequiredReading.pdf.

7. Maleck WH, Piper SN, Triem J, Boldt J, Zittel FU. Unexpected return of spontaneous circulation after cessation of resuscitation (Lazarus phenomenon) Resuscitation. 1998;39(1-2):125-8.

8. Kamarainen A, Virkkunen I, Holopainen L, Erkkila EP, Yli-Hankala A, Tenhunen J. Spontaneous defibrillation after cessation of resuscitation in out-of-hospital cardiac arrest: a case of Lazarus phenomenon. Resuscitation. 2007;75(3):543-6.

9. Adhiyaman V, Adhiyaman S, Sundaram R. The Lazarus phenomenon. J R Soc Med. 2007:100(12):552-7.

10. Maeda H, Fujita MQ, Zhu BL, Yukioka H, Shindo M, Quan L, et al. Death following spontaneous recovery from cardiopulmonary arrest in a hospital mortuary: 'Lazarus phenomenon' in a case of alleged medical negligence. Forensic Sci Int. 2002;127(1-2):82-7.

11. De Salvia A, Guardo A, Orrico M, De Leo D. A new case of Lazarus phenomenon? Forensic Sci Int. 2004;146(Suppl):S13-5.

12. Klein A, Lach H, Püschel K. Ein weiterer Fall von "Scheintod" - Diskussion über Richtlinien zur Todesfeststellung im Rettungswesen. Notfall Hausarztmedizin. 2007;33:330-5.

13. Puschel K, Lach H, Wirtz S, Moecke HP. Ein weiterer Fall von "Lazarus-Phänomen"? Notfall Rettungsmedizin. 2005;8:528-32.

14. Hornby L, Dhanani S, Shemie SD. Update of a Systematic Review of Autoresuscitation After Cardiac Arrest. Crit Care Med. 2018;46(3):e268-e72.

15. Munn Z, Peters MDJ, Stern C, Tufanaru C, McArthur A, Aromataris E. Systematic review or scoping review? Guidance for authors when choosing between a systematic or scoping review approach. BMC Med Res Methodol. 2018;18(1):143.

16. Tricco AC, Lillie E, Zarin W, O'Brien KK, Colquhoun H, Levac D, et al. PRISMA Extension for Scoping Reviews (PRISMA-ScR): Checklist and Explanation. Ann Intern Med. 2018:169(7):467-73.

17. Choquette $G$, Wasserman F, Lisker S, Bellet S. Spontaneous reversion of ventricular fibrillation to normal sinus rhythm in a case of acute myocardial infarction. Am Heart J. 1956;51(3):455-9.

18. Goble AJ. Paroxysmal Ventricular Fibrillation with Spontaneous Reversion to Sinus Rhythm. Br Heart J. 1965;27:62-8.

19. van Hemel NM, Kingma $\mathrm{JH}$. A patient in whom self-terminating ventricular fibrillation was a manifestation of myocardial reperfusion. Br Heart J. 1993; 69(6):568-71.

20. Mustafa MU, Baker CS, Stephens JD. Spontaneously terminating ventricular fibrillation and asystole induced by silent ischaemia causing recurrent syncope. Heart. 1998:80(1):86-8.

21. Cummins RO, Chamberlain DA, Abramson NS, Allen M, Baskett PJ, Becker L, et al. Recommended guidelines for uniform reporting of data from out-of-hospital cardiac arrest: the Utstein Style. A statement for health professionals from a task force of the American Heart Association, the European Resuscitation Council, the Heart and Stroke Foundation of Canada, and the Australian Resuscitation Council. Circulation. 1991:84(2):960-75.

22. Safar $P$. Resuscitation after brain ischemia. In: Grenvik A, Safar $P$, editors. Brain Failure and Resuscitation. New York: Churchill Livingstone; 1981. p. 155-84.

23. Gomes E, Araujo R, Abrunhosa R. Two successful cases of spontaneous recovery after cessation of CPR. Resuscitation. 1996;31.

24. Duff JP, Joffe AR, Sevcik W. deCaen A. Autoresuscitation after pediatric cardiac arrest: is hyperventilation a cause? Pediatr Emerg Care. 2011;27(3):208-9.

25. Vaux J, Reveaux F, Hauter A, Chollet-Xemard C, Marty J. Le phénomène de Lazare (French). Ann Fr Med Urgence. 2013;3:182-3.

26. Kuisma M, Salo A, Puolakka J, Nurmi J, Kirves H, Vayrynen T, et al. Delayed return of spontaneous circulation (the Lazarus phenomenon) after cessation of out-of-hospital cardiopulmonary resuscitation. Resuscitation. 2017:118:107-11.

27. Paal P, Milani M, Brown D, Boyd J, Ellerton J. Termination of cardiopulmonary resuscitation in mountain rescue. High Alt Med Biol. 2012;13(3):200-8.

28. Bossaert LL, Perkins GD, Askitopoulou H, Raffay Vl, Greif R, Haywood KL, et al. European Resuscitation Council Guidelines for Resuscitation 2015: Section 11. The ethics of resuscitation and end-of-life decisions. Resuscitation. 2015;95:302-11.

29. Drennan IR, Case E, Verbeek PR, Reynolds JC, Goldberger ZD, Jasti J, et al. A comparison of the universal TOR Guideline to the absence of prehospital 
ROSC and duration of resuscitation in predicting futility from out-of-hospital cardiac arrest. Resuscitation. 2017;111:96-102.

30. Morrison $\sqcup$, Eby D, Veigas PV, Zhan C, Kiss A, Arcieri V, et al. Implementation trial of the basic life support termination of resuscitation rule: reducing the transport of futile out-of-hospital cardiac arrests. Resuscitation. 2014;85(4):486-91.

31. Verhaert DV, Bonnes JL, Nas J, Keuper W, van Grunsven PM, Smeets JL, et al. Termination of resuscitation in the prehospital setting: A comparison of decisions in clinical practice vs. recommendations of a termination rule. Resuscitation. 2016;100:60-5.

32. Soar J, Nolan JP, Bottiger BW, Perkins GD, Lott C, Carli P, et al. European Resuscitation Council Guidelines for Resuscitation 2015: Section 3. Adult advanced life support. Resuscitation. 2015;95:100-47.

33. Hornby K, Hornby L, Shemie SD. A systematic review of autoresuscitation after cardiac arrest. Crit Care Med. 2010;38(5):1246-53.

34. Backer H, Kyburz A, Bosshard A, Babst R, Beeres FJP. Dead or dying? Pulseless electrical activity during trauma resuscitation. Br J Anaesth. 2017;118(5):809.

35. Duck MH, Paul M, Wixforth J, Kammerer $\mathrm{H}$. The Lazarus phenomenon. Spontaneous return of circulation after unsuccessful intraoperative resuscitation in a patient with a pacemaker. Anaesthesist. 2003;52(5):413-8.36

36. Wilseck Z, Cho K. Spontaneous circulation return after termination of resuscitation efforts for cardiac arrest following embolization of a ruptured common hepatic artery pseudoaneurysm. Gastrointes Interv. 2015;4:55-7.

37. Ekmektzoglou KA, Koudouna E, Bassiakou E, Stroumpoulis $K$, Clouva-Molyvdas $P$, Troupis $\mathrm{G}$, et al. An intraoperative case of spontaneous restoration of circulation from asystole: a case of lazarus phenomenon. Case Rep Emerg Med. 2012;2012: 380905.38.

38. Sahni V. The Lazarus phenomenon. JRSM Open. 2016;7(8):2054270416653523.

39. Yong SA, D'Souza S, Philpot S, Pilcher DV. The Alfred Hospital experience of resumption of cardiac activity after withdrawal of life-sustaining therapy. Anaesth Intensive Care. 2016;44(5):605-6.

40. Ali A, White P, Dhital K, Ryan M, Tsui S, Large S. Cardiac recovery in a human non-heart-beating donor after extracorporeal perfusion: source for human heart donation? J Heart Lung Transplant. 2009;28(3):290-3.

41. Mateos-Rodríguez A, Pardillos-Ferrer L, Navalpotro-Pascual JM. Kidney transplant function using organs from non-heart-beating donors maintained by mechanical chest compressions. Resuscitation. 2010;81:904-7.

42. Academy of Medical Royal C. A Code of Practice for the Diagnosis and Confirmation of Death 2008 [Available from: http://aomrc.org.uk/wp-content/ uploads/2016/04/Code_Practice_Confirmation_Diagnosis_Death_1008-4.pdf.

43. Zamperetti N, Bellomo R, Ronco C. Defining death in non-heart beating organ donors. J Med Ethics. 2003;29(3):182-5.

44. Dhanani S, Hornby L, Ward R, Baker A, Dodek P, Chamber-Evans J, et al. Vital signs after cardiac arrest following withdrawal of life-sustaining therapy: a multicenter prospective observational study. Crit Care Med. 2014;42(11):2358-69.

45. Bernat JL. How autoresuscitation impacts death determination in organ donation. Crit Care Med. 2010;38:1377-8.

46. Pani P, Giarrocco F, Giamundo M, Brunamonti E, Mattia M, Ferraina S. Persistence of cortical neuronal activity in the dying brain. Resuscitation. 2018;130:05-7.

47. Niemann JT, Stratton SJ, Cruz B, Lewis RJ. Outcome of out-of-hospital postcountershock asystole and pulseless electrical activity versus primary asystole and pulseless electrical activity. Crit Care Med. 2001;29(12):2366-70.

48. Rady MY, Verheijde JL. No-touch time in donors after cardiac death (nonheartbeating organ donation). Curr Opin Organ Transplant. 2013;18(2):140-7.

49. Halpern SD, Truog RD. Organ donors after circulatory determination of death: not necessarily dead, and it does not necessarily matter. Crit Care Med. 2010; 38(3):1011-2.

50. Braun P, Herff H, Paal P. The Lazarus phenomenon-false positive death certifications and auto-resuscitation cases covered in lay press. Resuscitation. 2011;82(10):1363-4

51. Rady MY, Verheijde JL. Lazarus phenomenon, autoresuscitation, and nonheart-beating organ donation. Crit Care Med. 2010;38(8):1757-8 author reply 8-9.

52. Kompanje EJ, de Groot YJ. Autoresuscitation is not a determinant to lower the observation time in declaring death for organ donation. Crit Care Med. 2012;40(2):708 author reply 9 .

53. Rady MY, Verheijde JL. Autoresuscitation and determining circulatoryrespiratory death in clinical practice for organ donation. Crit Care Med. 2012:40(5):1655-6.

54. Woodside KJ. Autoresuscitation and organ donation: when is it safe to declare someone dead? Crit Care Med. 2012;40(1):329-30.
55. Rady MY, Verheijde JL. Lazarus phenomenon and clinical practice guidelines for death diagnosis: regaining public trust in medical practice. Resuscitation. 2014;85(4):e63.

56. Sheth KN, Nutter T, Stein DM, Scalea TM, Bernat JL. Autoresuscitation after asystole in patients being considered for organ donation. Crit Care Med. 2012;40(1):158-61.

57. Veatch RM. Are Organ Donors Really Dead: The Near-Irrelevance of Autoresuscitation. Am J Bioeth. 2018;18(8):1-2.

58. Weiss MJ, Sherry W, Hornby L. Pediatric donation after circulatory determination of death (pDCD): A narrative review. Paediatr Respir Rev. 2019;29:3-8.

59. Rosengarten PL, Tuxen DV, Dziukas L, Scheinkestel C, Merrett K, Bowes G. Circulatory arrest induced by intermittent positive pressure ventilation in a patient with severe asthma. Anaesth Intensive Care. 1991;19(1):118-21.

60. Krarup NH, Kaltoft A, Lenler-Petersen P. Risen from the dead: a case of the Lazarus phenomenon-with considerations on the termination of treatment following cardiac arrest in a prehospital setting. Resuscitation. 2010;81(11): 1598-9.

61. Walker A, McClelland $\mathrm{H}$, Brenchley J. The Lazarus phenomenon following recreational drug use. Emerg Med J. 2001;18(1):74-5.

62. Adanali M, Güvenç TS, Kale MY. Lazarus phenomenon in a patient with Duchenne muscular dystrophy and dilated cardiomyopathy. J Acute Med. 2014:4:99-102.

63. Letellier N, Coulomb F, Lebec C, Brunet JM. Recovery after discontinued cardiopulmonary resuscitation. Lancet. 1982;1 (8279):1019.

64. Ben-David B, Stonebraker VC, Hershman R, Frost CL, Williams HK. Survival after failed intraoperative resuscitation: a case of "Lazarus syndrome". Anesth Analg. 2001;92(3):690-2.

65. Spowage-Delaney B, Edmunds CT, Cooper JG. The Lazarus phenomenon: spontaneous cardioversion after termination of resuscitation in a Scottish hospital. BMJ Case Rep. 2017;2017.

66. Torbado A, Pellejero S, Uriz J, Pavon A, Salvador M. No neurological impairment after a case of Lazarus phenomenon. Eur J Anaesthesiol. 2006; 23:214 (A829).

67. Quick G, Bastani B. Prolonged asystolic hyperkalemic cardiac arrest with no neurologic sequelae. Ann Emerg Med. 1994;24(2):305-11.

68. Pasquier M, de Riedmatten M, Paal P. Autoresuscitation in Accidental Hypothermia. Am J Med. 2018;131(9):e367-e8.

69. Vorotyntsev SI, Goldovsky BM, Potalov SA, Serikov KV, Serbin VG, Nikolayenko AM, et al. The Phenomenon of Lazarus - Autoresuscitation after cardiac arrest (Russian) 2011 Available from: https://cyberleninka.ru/article/n/fenomen-lazaryaautoresustsitatsiya-posle-ostanovki-serdtsa.

70. Fumeaux T, Borgeat A, Cuenoud PF, Erard A, de Werra P. Survival after cardiac arrest and severe acidosis $(\mathrm{pH}=6.54)$. Intensive Care Med. 1997; 23(5):594.

71. Meeker JW, Kelkar AH, Loc BL, Lynch TJ. A Case Report of Delayed Return of Spontaneous Circulation: Lazarus Phenomenon. Am J Med. 2016;129(12):e343-e4.

72. Tretter JT, Radunsky GS, Rogers DJ, Daugherty LE. A pediatric case of autoresuscitation. Pediatr Emerg Care. 2015;31(2):138-9.

73. Mullen S, Roberts Z, Tuthill D, Owens L, Te Water Naude J, Maguire S. Lazarus Syndrome - Challenges Created by Pediatric Autoresuscitation. Pediatr Emerg Care. 2018.

74. Huang Y, Kim S, Dharia A, Shalshin A, Dauer J. Delayed recovery of spontaneous circulation following cessation of cardiopulmonary resuscitation in an older patient: a case report. J Med Case Rep. 2013;7:65.

75. Rogers PL, Schlichtig R, Miro A, Pinsky M. Auto-PEEP during CPR. An "occult" cause of electromechanical dissociation? Chest. 1991;99(2):492-3.

76. MacGillivray RG. Spontaneous recovery after discontinuation of cardiopulmonary resuscitation. Anesthesiology. 1999;91(2):585-6.

77. Hagmann H, Oelmann K, Stangl R, Michels G. Is increased positive endexpiratory pressure the culprit? Autoresuscitation in a 44-year-old man after prolonged cardiopulmonary resuscitation: a case report. J Med Case Rep. 2016;10(1):364.

78. Martens $\mathrm{P}$, Vandekerckhove $\mathrm{Y}$, Mullie A. Restoration of spontaneous circulation after cessation of cardiopulmonary resuscitation. Lancet. 1993; 341(8848):841.

79. Al-Ansari MA, Abouchaleh NM, Hijazi MH. Return of spontaneous circulation after cessation of cardiopulmonary resuscitation in a case of digoxin overdosage. Clin Intensive Care. 2005;16:179-81.

80. Bradbury N. Lazarus phenomenon: another case? Resuscitation. 1999; $41(1): 87$. 
81. Hannig KE, Hauritz RW, Grove EL. Autoresuscitation: A Case and Discussion of the Lazarus Phenomenon. Case Rep Med. 2015;2015:724174.

82. Cummings BM, Noviski N. Autoresuscitation in a child: The young Lazarus. Resuscitation. 2011:82(1):134.

83. Garcia JLC, Gonzalez-Latorre MV, Fernandez AN. El fenómeno de Lázaro: Reanimación espontánea (Spanish). Rev Esp Anestesiol Reanim. 2004;51:390-4.

84. Low DW, Looi I, Manocha AB, Ang HA, Nagalingam M, Ayop NA, et al. Rising from the dead! Med J Malaysia. 2012;67(5):538-9.

85. Mutzbauer TS, Stahl W, Lindner KH. Compression-decompression (ACD)-CPR. Prehosp Disaster Med. 1997;12:S21.

86. Aguado OR, Portilla FJS, Ruiz JPN. Lazarus phenomenon in an out-of-hospital emergency attended by a home emergency service. Emergencias. 2011;23:43-6.

87. Tiesmeier J, Brandt O, Emmerich M. Unerwartete Lebenszeichen nach erfolgloser Reanimation (German). MMW Fortschr ed. 2010;152:33-6.

88. Thong SY, Ng SY. Case report - Lazarus syndrome after prolonged resuscitation: Herbert Publications Ltd; 2013. Available from: http://www. hoajonline.com/journals/pdf/2049-9752-2-14.pdf

89. Voelckel W, Kroesen G. Unexpected return of cardiac action after termination of cardiopulmonary resuscitation. Resuscitation. 1996;32(1):27-9.

90. Monticelli F, Bauer N, Meyer HJ. Lazarus-Phänomen Aktueller Stand der Reanimation und Fragen an den medizinischen Gutachter (German). Anaesthesist. 2006:16.

91. Wiese CHR, Stojanovic T, Klockgether-Radke A, Bartels U, Schmitto JD, Quintel M, et al. Intraoperatives "Lazarus-Phänomen"? Spontane Kreislaufstabilisierung bei einem Patienten mit Herzschrittmacher (German). Anaesthesist. 2007:56:1231-6.

92. Güven AT, Petridis G, Özkal SS, Kalfoglu EA. Lazarus Phenomenon in Medicolegal Perspective: A case report (Turkish). Adli Tip Bülteni. 2017;22(3):224-7.

93. Jasra S, Majumdar S, Rajagopalan B, Fernandez S. Lazarus syndrome. A rare case of auto-resuscitation: American College of Physicians Annual Scientific Meeting - poster competition 2015 Available from: https://www.nyacp.org/ files/callforpapers/2015\%20Poster\%20Book.pdf.

94. Alves S, Campos M, Reis G. Lazarus syndrome in the emergency room: A case report. Resuscitation. 2010;84:e151.

95. Sukhyanti K, Shrikrishan C, Anu K, Ashish D. Lazarus phenomenon revisited: a case of delayed return of spontaneous circulation after carbon dioxide embolism under laparoscopic cholecystectomy. Anaes Pain Int Care. 2012.

96. Frolich MA. Spontaneous recovery after discontinuation of intraoperative cardiopulmonary resuscitation: case report. Anesthesiology. 1998;89(5):1252-3.

97. Bray JG Jr. The Lazarus phenomenon revisited. Anesthesiology. 1993;78(5):991.

98. Abdullah RS. Restoration of circulation after cessation of positive pressure ventilation in a case of "Lazarus syndrome". Anesth Analg. 2001;93(1):241.

99. Mustamam AHM, Jailani AFMAK, Z'aba N, Balakrishnan SL, Ali NM. Arise from the dead - case report. Malaysian J Emerg Med. 2016;1:49.

100. Wiener C. Ventilatory management of respiratory failure in asthma. JAMA. 1993;269(16):2128-31.

101. Lapinsky SE, Leung RS. Auto-PEEP and electromechanical dissociation. N Engl J Med. 1996;335(9):674.

102. Manara AR, Thomas I. The use of circulatory criteria to diagnose death after unsuccessful cardiopulmonary resuscitation. Resuscitation. 2010:81 (7):781-3.

103. Connery LE, Deignan MJ, Gujer MW, Richardson MG. Cardiovascular collapse associated with extreme iatrogenic PEEPi in patients with obstructive airways disease. Br J Anaesth. 1999;83(3):493-5.

104. Aufderheide TP, Lurie KG. Death by hyperventilation: a common and lifethreatening problem during cardiopulmonary resuscitation. Crit Care Med. 2004;32(9 Suppl):S345-51.

105. Paradis NA, Martin GB, Rivers EP, Goetting MG, Appleton TJ, Feingold M, et al. Coronary perfusion pressure and the return of spontaneous circulation in human cardiopulmonary resuscitation. JAMA. 1990;263(8):1106-13.

106. Peña SB, Aedo IF, Palomino SL. Spontaneous return of circulation after termination of cardiopulmonary resuscitation maneuvers: a systematic review of cases of Lazarus phenomenon. Emergencias. 2014;26:307-16.

107. DeVita MA. The death watch: certifying death using cardiac criteria. Prog Transplant. 2001;11(1):58-66.

\section{Publisher's Note}

Springer Nature remains neutral with regard to jurisdictional claims in published maps and institutional affiliations.

Ready to submit your research? Choose BMC and benefit from:

- fast, convenient online submission

- thorough peer review by experienced researchers in your field

- rapid publication on acceptance

- support for research data, including large and complex data types

- gold Open Access which fosters wider collaboration and increased citations

- maximum visibility for your research: over $100 \mathrm{M}$ website views per year

At $\mathrm{BMC}$, research is always in progress.

Learn more biomedcentral.com/submissions 